\title{
Effect of Salt Stress on Na Accumulation, Antioxidant Enzyme Activities and Activity of Cell Wall Peroxidase of Huckleberry (Solanum scabrum) and Eggplant (Solanum melongena)
}

\author{
Dekoum Vincent Marius Assaha, Liyun Liu, Ahmad Mohammad M. Mekawy, Akihiro Ueda, Toshinori \\ Nagaoka and Hirofumi Saneoka* \\ Graduate School of Biosphere Science, Hiroshima University, 1-4-4 Kagamiyama, Higashi-Hiroshima, 739-8528, Japan \\ *For correspondence: saneoka@hiroshima-u.ac.jp
}

\begin{abstract}
Understanding the adaptive mechanisms to salinity stress is an important prerequisite for crop improvement and sustainable production. The objective of this study was to compare the adaptation of huckleberry and eggplant to salinity in terms of total dry weight, malondialdehyde (MDA) content, the activities of catalase (CAT), ascorbate peroxidase (APX), glutathione reductase (GR), soluble peroxidases (sPOD) and peroxidases ionically-bound to cell wall (cwPOD) and $\mathrm{Na}^{+}$and $\mathrm{K}^{+}$concentrations. Growth was found to be more reduced in eggplant (63\% reduction) than huckleberry (51\% reduction). $\mathrm{Na}^{+}$ concentration was 2.5-fold higher in leaf of eggplant than huckleberry. The MDA content significantly increased in root and leaf of eggplant, but remained unchanged in huckleberry. In the leaf of huckleberry, cwPOD alone was significantly enhanced by salt stress, whereas in the root all the enzymes except CAT were significantly elevated. In eggplant on the contrast, cwPOD activity tended to decrease in leaf and root, whereas CAT markedly increased in the leaf, but sharply declined in the root. APX activity in eggplant slightly increased in both root and leaf while sPOD significantly increased in the root but remained unaltered in the leaf. These results suggest that $\mathrm{Na}^{+}$exclusion in the leaf blade and greater antioxidant activity in the root constitute important adaptations to salt stress in huckleberry. Particularly, cwPOD activity in the leaf and root of huckleberry suggest a dual role in the adaptation; mainly reactive oxygen species detoxification in leaf and enhanced lignin deposition in root, which functions in controlling root-to-shoot $\mathrm{Na}^{+}$delivery. (C) 2015 Friends Science Publishers
\end{abstract}

Keywords: $\mathrm{Na}^{+}$distribution; Oxidative stress; Catalase; Ascorbate peroxidase; Glutathione reductase

\section{Introduction}

Under salinity stress conditions, one of the main factors of growth inhibition is oxidative stress damage (Munns and Tester, 2008). Oxidative stress is a secondary stress arising from either loss of electrons to oxygen during metabolic processes such as photosynthesis, respiration and photorespiration or reaction of activated oxygen with photosensitized chlorophyll, both of which lead to the generation of reactive oxygen species (ROS) (Mittler, 2002; Sharma et al., 2012). These ROS include singlet oxygen $\left({ }^{1} \mathrm{O}_{2}\right)$, the super anion $\left(\mathrm{O}_{2}^{-}\right)$, hydrogen peroxide $\left(\mathrm{H}_{2} \mathrm{O}_{2}\right)$ and hydroxyl radical $(\mathrm{HO} \bullet)$ and are produced in various subcellular compartments including chloroplasts, mitochondria, peroxisomes, endoplasmic reticulum, plasma membranes, cell walls and apoplasts (Abogadallah, 2010; Sharma et al., 2012). If their production is not tightly controlled, they may affect plant metabolism by, denaturing proteins and nucleic acids, inducing lipid peroxidation and even cell death (Gill and Tuteja, 2010).

The detoxification of ROS constitutes an important trait in salt stress tolerance. This detoxification is achieved by the activity of antioxidants, which can be enzymatic, for example CAT, APX, GR and SOD, or non-enzymatic, for example ascorbic acid, flavonoids, total phenolics, carotenoids and tocopherol (Abogadallah, 2010; Gill and Tuteja, 2010; Sharma et al., 2012). Reduction in antioxidant activity will lead to increased oxidative damage, which is often seen as increased MDA content, a product of lipid peroxidation, whereas an increase in enzyme activity will correlate with low MDA, hence tolerance (Demiral and Türkan, 2005; Koca et al., 2007). In addition, Sairam and Tyagi (2004) observed an inverse correlation between high SOD, CAT and GR activities, and low MDA, membrane stability index and $\mathrm{Na}^{+} / \mathrm{K}^{+}$ratio in the tolerant wheat cultivars under salinity stress. This suggests that, the maintenance of low $\mathrm{Na}^{+} / \mathrm{K}^{+}$ratios, especially in the photosynthetic tissues, through shoot $\mathrm{Na}^{+}$exclusion mechanisms occurring in the lower parts of the plant, may minimize oxidative damage and increase tolerance to salinity (Dionisio-Sese and Tobita, 1998).

The roots are always in direct contact with saline

To cite this paper: Assaha, D.V.M., L. Liu, A.M.M. Mekawy, A. Ueda, T. Nagaoka and H. Saneoka, 2015. Effect of salt stress on Na accumulation, antioxidant enzyme activities and activity of cell wall peroxidase of huckleberry (Solanum scabrum) and eggplant (Solanum melongena). Int. J. Agric. Biol., 17: 1149-1156 
environments and have been shown to serve as control points for root-to-shoot $\mathrm{Na}^{+}$delivery. For example, many transporters responsible for regulating $\mathrm{Na}^{+}$uptake and transport to the leaf have been identified in the root, including the salt overly sensitive (SOS1) transporter and the high affinity $K^{+}$transporter (HKT) (Tester and Davenport, 2003; Munns and Tester, 2008; Møller et al., 2009). Furthermore, antioxidant enzyme activities in roots have been found to play crucial roles in salinity tolerance, by scavenging ROS (Demiral and Türkan, 2005; Jaleel et al., 2007). In addition, peroxidases ionically-bound to cell wall are involved in the synthesis of lignin, a constituent of the Casparian strip in the root, which functions in restricting the passage of solutes including $\mathrm{Na}^{+}$to the stele (Lee et al., 2013). Enhanced cwPOD under salinity has been found to protect plants by scavenging ROS (Maia et al., 2013), as well as correlates with enhanced deposition of lignin, which has been suggested to control the transport of $\mathrm{Na}^{+}$to the shoot (Jbir et al., 2001). Thus, cwPOD activity may be an important attribute in salinity stress tolerance. These observations suggest that, changes occurring in root in response to salt stress are important for stress tolerance and thus may define the overall adaptation of a plant under such environments. Understanding these changes may offer new targets for molecular engineering of salinity tolerance in crops.

Huckleberry (Solanum scabrum Mill.) and eggplant (Solanum melongena L.) are two solanaceous vegetables that differ in the pattern of $\mathrm{Na}^{+}$accumulation (Assaha et al., 2013). Huckleberry accumulates very low $\mathrm{Na}^{+}$in leaf and more in root and stem, while eggplant accumulates more in leaf and less in root and stem. It is this uncontrolled accumulation of $\mathrm{Na}^{+}$in eggplant that is thought to be responsible for its growth reduction under salt stress (Shaheen et al., 2012; Assaha et al., 2013). Excess accumulation of $\mathrm{Na}^{+}$in the leaf of the eggplant cultivar, New Nobel, was shown to correlate with increased $\mathrm{H}_{2} \mathrm{O}_{2}$ and MDA production, indicating $\mathrm{Na}^{+}$-induced oxidative damage (Shaheen et al., 2012). In this study, the excess $\mathrm{Na}^{+}$ accumulation was also accompanied by an increase in SOD, POD and CAT activities, but this increased enzyme activity did not correlate with tolerance in the eggplant cultivar studied, indicating the overwhelming effects of high $\mathrm{Na}^{+}$ accumulation on antioxidant defense system in the leaf of eggplant.

No information on the injury and enzyme activity at the level of the root has been established in eggplant, while antioxidant activity in huckleberry is non-existent. Since high $\mathrm{Na}$ accumulation induces oxidative stress damage it is expected that high salt accumulation in root of huckleberry would be deleterious, whereas this damage would be reduced in the leaf, where less $\mathrm{Na}$ is accumulated. In eggplant on the contrast with lower $\mathrm{Na}$ accumulation in the root, oxidative stress should be more pronounced in the leaf. Thus, the objective of this study was to compare $\mathrm{Na}^{+}$ accumulation in different organs and evaluate the antioxidant enzyme activity in the leaf and root of huckleberry and eggplant under high salt stress.

\section{Materials and Methods}

\section{Plants and Growth Conditions}

The huckleberry and eggplant used in this study were the same as described in Assaha et al. (2013). Seeds of both plants were sown in seed beds, transferred 4 weeks after germination to $2 \mathrm{~L}$ pots, filled with a mixture of regosol soil, perlite and peat moss $(2: 1: 1, \mathrm{v} / \mathrm{v})$ and irrigated with $1 / 4$ nutrient solution for $10 \mathrm{~d}$. Thereafter, the plants were arranged in a randomized complete block design with 4 groups of 4 replicates each and irrigated with $1 / 2$ strength nutrient solution, supplemented with 0 (for control) and 150 (stressed) $\mathrm{mM} \mathrm{NaCl}$ to induce salinity stress. The composition of the nutrient solution was as described by Assaha et al. (2013). The $\mathrm{NaCl}$ solution was applied at 50 $\mathrm{mM}$ increments every day until the maximum concentration $(150 \mathrm{mM})$ was reached, at which point start of treatment was considered.

\section{Determination of Growth, $\mathrm{Na}^{+}$and $\mathrm{K}^{+}$Concentrations, and Enzyme Activities}

After $10 \mathrm{~d}$ of salt treatment, samples were collected for analysis. The plants were separated into root, stem, petiole and leaf blade and their fresh weights (FW) recorded. Then, portions of these samples were frozen in liquid nitrogen stored at $-80^{\circ} \mathrm{C}$, while the rest were oven-dried and their dry weights (DW) recorded.

$\mathrm{Na}^{+}$and $\mathrm{K}^{+}$concentrations were determine using freeze-dried samples of leaf blade, petiole, stem and root. The samples were powdered, digested with $\mathrm{HNO}_{3} / \mathrm{H}_{2} \mathrm{O}_{2}(1$ : $1, \mathrm{v} / \mathrm{v}$ ) and measured using a flame photometer (ANA 135, Tokyo Photoelectric, Tokyo, Japan).

The MDA content in leaf and root was determined by the thiobarbituric acid (TBA) reaction as described by Saneoka et al. (2004) with some modifications. Fresh leaf and root samples $(0.1 \mathrm{~g})$ were homogenized in an extraction buffer (10 mM HEPES, pH 7, 15\% tricarboxylic acid, $0.375 \%$ thiobarbituric acid, $0.25 \mathrm{~N} \mathrm{HCl}, 0.04 \%$ butylated hydroxyl toluene and $2 \%$ ethanol), incubated at $95^{\circ} \mathrm{C}$ and then centrifuged. The absorbance of the supernatant was then read at $535 \mathrm{~nm}$ and $600 \mathrm{~nm}$ and the MDA content was calculated using the extinction coefficient $\left(155 \mathrm{mM}^{-1} \mathrm{~cm}^{-1}\right)$ (Dionisio-Sese and Tobita, 1998).

The protein concentration in enzyme extract was measured using the Protein Assay kit (Bio-Rad DC, California, USA) with bovine serum albumin as standard, according to manufacturer's instructions. For the activities of catalase (CAT, EC 1.11.1.6), as corbate peroxidase (APX, EC 1.11.1.11) and glutathione reductase (GR, EC 1.6.4.2), enzyme extraction was carried out using $0.5 \mathrm{~g}$ fresh sample according to the method of Takagi and Yamada (2013). 
One mL CAT assay mixture contained $50 \mathrm{mM}$

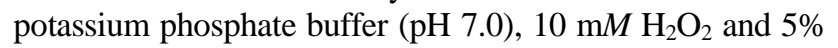
enzyme extract. A decrease in $\mathrm{H}_{2} \mathrm{O}_{2}$ was followed at $240 \mathrm{~nm}$ and activity calculated as $\mathrm{mmol} \mathrm{H}_{2} \mathrm{O}_{2}$ consumed per minute. For APX activity, $1 \mathrm{~mL}$ assay mixture contained $25 \mathrm{mM}$ phosphate buffer (pH 7.0), $0.25 \mathrm{mM}$ ascorbic acid, $0.1 \mathrm{~m} M$

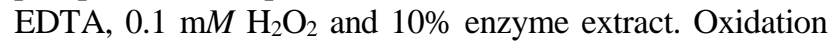
of ascorbate was measured at $290 \mathrm{~nm}$ and its concentration calculated using the extinction coefficient of $2.8 \mathrm{~m}^{-1} \mathrm{~cm}^{-1}$. One unit APX was determined as $1 \mu \mathrm{mol}$ as corbate oxidized per minute. For GR activity, $1 \mathrm{~mL}$ assay mixture contained $100 \mathrm{~m} M$ phosphate buffer (pH 7.5), $0.1 \mathrm{mM}$ EDTA, $0.02 \mathrm{~m} M$ NADPH, $0.02 \mathrm{~m} M$ GSSG and $10 \%$ enzyme extract. Concentration of oxidized NADPH was determined using the extinction coefficient $\left(6.22 \mathrm{mM}^{-1} \mathrm{~cm}^{-1}\right)$ and 1 unit GR activity defined as $\mu$ mol NADPH oxidized per min.

Extraction of soluble peroxidases (sPOD) and peroxidases ionically bound to cell wall (cwPOD) was carried out on fresh leaf and root samples. Samples $(0.5 \mathrm{~g})$ were ground in liquid nitrogen, to which phosphate buffer was added ( $\mathrm{pH} 7.0)$. The homogenate was then centrifuged and the supernatant collected for the determination of sPOD. Then, cwPOD was subsequently extracted from the residual pellet as described by Lin and Kao (2001). For the measurement of sPOD activity, $1 \mathrm{~mL}$ reaction mixture contained $15 \mathrm{~m} M$ guaiacol, $73 \mathrm{~m} M$ phosphate buffer, 10 $\mathrm{mM} \mathrm{H} \mathrm{H}_{2} \mathrm{O}_{2}$ and $2 \%$ enzyme extract. Increase in absorbance was monitored at $470 \mathrm{~nm}$ for $1 \mathrm{~min}$ and the enzyme activity calculated using the extinction coefficient $\left(26.6 \mathrm{~m} M^{-1} \mathrm{~cm}^{-1}\right)$ for tetraguaiacol (Chance and Maehly, 1955). One unit sPOD activity was defined as mmol tetraguaiacol formed per min. For cwPOD activity, the reaction mixture contained $0.2 \mathrm{~m} M$ syringaldazine as substrate, $0.1 \mathrm{~m} M$ $\mathrm{H}_{2} \mathrm{O}_{2}, 68 \mathrm{~m} M$ phosphate buffer and $2 \%$ enzyme extract. Increase in absorbance at $530 \mathrm{~nm}$ was monitored for $1 \mathrm{~min}$ and enzyme activity calculated using the extinction coefficient $\left(27 \mathrm{mM}^{-1} \mathrm{~cm}^{-1}\right)$ (Quiroga et al., 2000). One unit cwPOD activity was defined as mmol syringaldazine oxidized per min. The protein concentration in both extracts was measured as described above.

\section{Statistical Analysis}

All data were analyzed by one way analysis of variance using the SPSS statistical package version 21 (IBM Inc. USA). All results are means $\pm \mathrm{SE}(\mathrm{n}=4)$ and the means were separated using the Duncan Multiple Range Test at $\mathrm{p}=$ 0.05 .

\section{Results}

\section{Effect of Salinity on Plant Biomass}

The DW of leaf blade, petiole, stem and root of both plants are presented in Table 1. The growth of both plants was

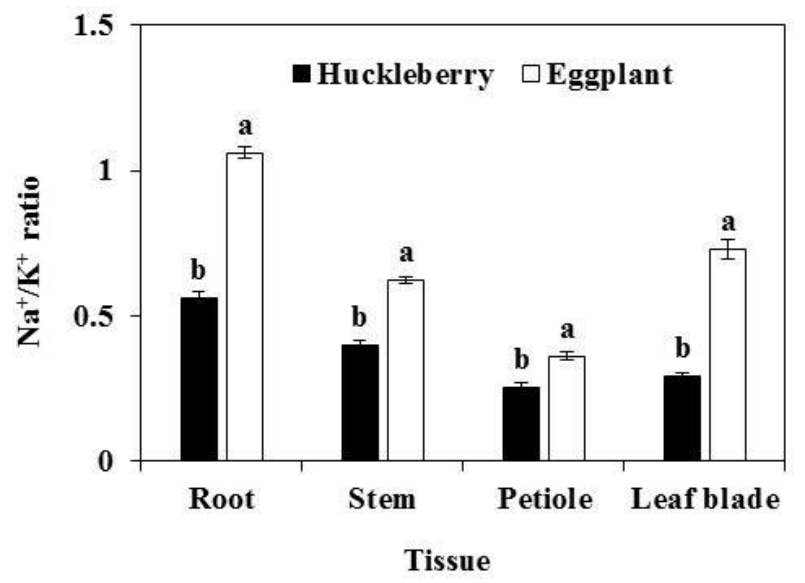

Fig. 1: Effect of salinity on $\mathrm{Na}^{+} / \mathrm{K}^{+}$ratio in the different tissues of huckleberry and eggplant.The result represents the means $\pm \operatorname{SE}(n=4)$. Different letters for each tissue indicate significant difference $(\mathrm{p} \leq 0.05)$

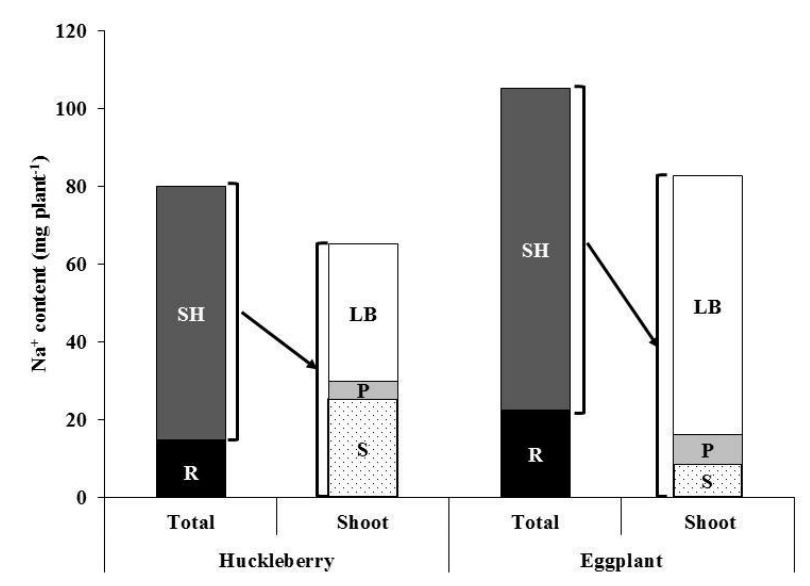

Fig. 2: The Distribution of $\mathrm{Na}^{+}$accumulated by huckleberry and eggplant under salt stress. $\mathrm{LB}=$ leaf blade, $\mathrm{S}=$ stem, $\mathrm{P}$ $=$ petiole, $\mathrm{R}=$ root, $\mathrm{SH}=$ shoot

reduced by salinity stress. However, the decrease was more marked in eggplant (63\% reduction) than huckleberry (51\% reduction). Leaf DW reduction was lesser in huckleberry $(47 \%)$ than in eggplant (68\%). Reduction in petiole DW was also greater in eggplant $(65 \%)$ than in huckleberry (51\%). However, whereas stem DW reduction was similar for both plant species, whilst root DW reduction was more marked in huckleberry (49\%) than eggplant (25\%).

\section{Effect of Salinity on $\mathrm{Na}^{+}$and $\mathrm{K}^{+}$Accumulation}

The concentrations of $\mathrm{Na}^{+}$in the different tissues of both plants are presented in Table 2. Leaf $\mathrm{Na}^{+}$concentration was 2.5 -fold higher in eggplant than in huckleberry, whereas stem $\mathrm{Na}^{+}$concentration was $53 \%$ higher in huckleberry than 
Table 1: Effect of salinity stress on the dry weight of leaf blade (LB), petiole, stem and root of huckleberry and eggplant

\begin{tabular}{|c|c|c|c|c|c|c|}
\hline Plant & Treatments $(\mathrm{mM} \mathrm{NaCl})$ & LB DW $\left(\right.$ g plant $\left.^{-1}\right)$ & Petiole DW $\left(\mathrm{g}_{\text {plant }}{ }^{-1}\right)$ & Stem DW $\left(\right.$ g plant $\left.^{-1}\right)$ & Root DW $\left(\right.$ g plant $\left.^{-1}\right)$ & Total DW $\left(\right.$ g plant $\left.^{-1}\right)$ \\
\hline Huckleberry & 0 & $5.23 \pm 0.24^{b}$ & $0.43 \pm 0.02^{\mathrm{b}}$ & $2.25 \pm 0.11^{\mathrm{a}}$ & $1.45 \pm 0.05^{\mathrm{a}}$ & $9.35 \pm 0.29^{a}$ \\
\hline & 150 & $2.77 \pm 0.08^{\mathrm{c}}$ & $0.21 \pm 0.01^{\mathrm{b}}$ & $0.81 \pm 0.03^{\mathrm{c}}$ & $0.74 \pm 0.04^{\mathrm{c}}$ & $4.53 \pm 0.11^{\mathrm{b}}$ \\
\hline Eggplant & $\begin{array}{l}0 \\
150\end{array}$ & $\begin{array}{l}6.15 \pm 0.25^{\mathrm{a}} \\
1.94 \pm 0.04^{\mathrm{d}}\end{array}$ & $\begin{array}{l}0.84 \pm 0.14^{\mathrm{a}} \\
0.29 \pm 0.02^{\mathrm{b}}\end{array}$ & $\begin{array}{l}1.20 \pm 0.01^{\mathrm{b}} \\
0.42 \pm 0.04^{\mathrm{d}}\end{array}$ & $\begin{array}{l}0.97 \pm 0.16^{\mathrm{bc}} \\
0.73 \pm 0.04^{\mathrm{c}}\end{array}$ & $9.15 \pm 0.19^{\mathrm{a}}$ \\
\hline
\end{tabular}

Values are means $\pm S E(n=4)$ at $\mathrm{p} \leq 0.05$. For each column means followed by same letter are not significantly different

Table 2: Effect of salinity on $\mathrm{Na}^{+}$concentration in leaf blade, petiole, stem and root of huckleberry and eggplant

\begin{tabular}{|c|c|c|c|c|c|}
\hline \multirow[t]{2}{*}{ Plant } & \multirow[t]{2}{*}{ Treatment $(\mathrm{mM} \mathrm{NaCl})$} & \multicolumn{4}{|c|}{$\mathrm{Na}^{+}(\mathrm{mg} / \mathrm{g}$ DW $)$} \\
\hline & & Leaf blade & Petiole & Stem & Root \\
\hline Huckleberry & 0 & $0.22 \pm 0.01^{\mathrm{d}}$ & $0.37 \pm 0.02^{\mathrm{d}}$ & $0.50 \pm 0.04^{\mathrm{d}}$ & $1.12 \pm 0.04^{\mathrm{d}}$ \\
\hline & 150 & $12.79 \pm 0.77^{\mathrm{c}}$ & $20.86 \pm 1.34^{\mathrm{b}}$ & $31.23 \pm 1.17^{\mathrm{a}}$ & $20.17 \pm 0.27^{b}$ \\
\hline Eggplant & 0 & $0.96 \pm 0.06^{\mathrm{d}}$ & $1.63 \pm 0.13^{c}$ & $1.32 \pm 0.08^{\mathrm{c}}$ & $2.66 \pm 0.54^{\mathrm{c}}$ \\
\hline & 150 & $34.53 \pm 1.80^{\mathrm{a}}$ & $26.01 \pm 0.90^{\mathrm{a}}$ & $20.44 \pm 0.36^{\mathrm{b}}$ & $31.01 \pm 0.37^{\mathrm{a}}$ \\
\hline
\end{tabular}

Values are means $\pm \mathrm{SE}(\mathrm{n}=4)$ at $\mathrm{p} \leq 0.05$. For each column means followed by same letter are not significantly different

Table 3: Effect of salinity on $\mathrm{K}^{+}$concentration in leaf blade, petiole, stem and root of huckleberry and eggplant

\begin{tabular}{llllll}
\hline Plant & Treatment $(\mathrm{mM} \mathrm{NaCl})$ & \multicolumn{3}{c}{$\mathrm{K}^{+}(\mathrm{mg} / \mathrm{g}$ DW $)$} \\
\cline { 3 - 6 } & & Leaf blade & Petiole & Stem & Root \\
\hline Huckleberry & 0 & $46.83 \pm 0.51^{\mathrm{b}}$ & $86.06 \pm 0.49^{\mathrm{a}}$ & $82.59 \pm 1.22^{\mathrm{a}}$ & $47.16 \pm 0.91^{\mathrm{a}}$ \\
& 150 & $43.46 \pm 0.50^{\mathrm{c}}$ & $82.62 \pm 0.95^{\mathrm{b}}$ & $77.43 \pm 0.99^{\mathrm{b}}$ & $35.74 \pm 0.87^{\mathrm{b}}$ \\
Eggplant & 0 & $65.94 \pm 2.13^{\mathrm{a}}$ & $83.39 \pm 1.74^{\mathrm{b}}$ & $64.77 \pm 1.22^{\mathrm{c}}$ & $46.08 \pm 0.90^{\mathrm{a}}$ \\
& 150 & $47.53 \pm 0.57^{\mathrm{b}}$ & $73.04 \pm 1.08^{\mathrm{c}}$ & $33.21 \pm 0.29^{\mathrm{d}}$ & $29.28 \pm 0.30^{\mathrm{c}}$ \\
\hline
\end{tabular}

Values are means $\pm \operatorname{SE}(n=4)$ at $\mathrm{p} \leq 0.05$. For each column means followed by same letter are not significantly different

A

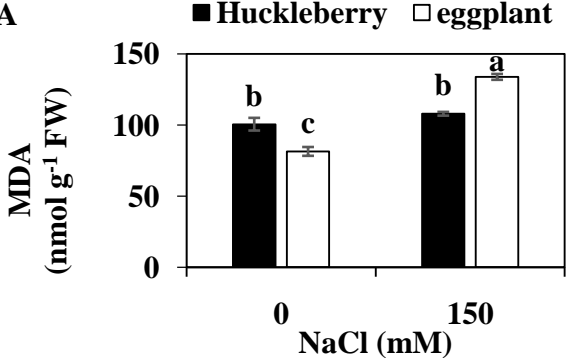

B

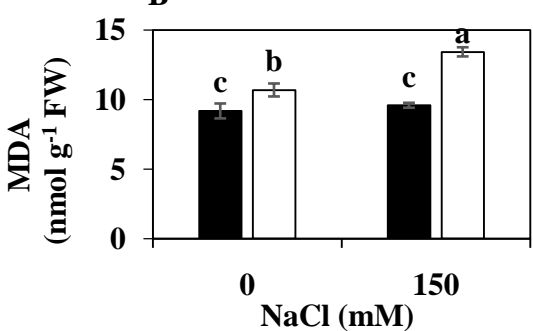

Fig. 3: Effect of salinity on MDA content in leaf (A) and root (B) of huckleberry and eggplant. The results represent the means $\pm \operatorname{SE}(n=4)$. The same letter indicates no significant difference $(\mathrm{p} \leq 0.05)$

eggplant. In the root and petiole, $\mathrm{Na}^{+}$concentration was more elevated in eggplant. $\mathrm{K}^{+}$concentration decreased in all the studied tissues of both plants, but this reduction was more marked in eggplant than huckleberry, especially in the leaf, stem and root (28, 49 and $36 \%$, respectively; Table 3 ). The $\mathrm{Na}^{+} / \mathrm{K}^{+}$ratio was found to be more elevated for all the studied tissues in eggplant, especially in the root where it was above 1 (Fig. 1).

The total $\mathrm{Na}^{+}$content and its distribution in the root, stem, petiole and leaf blade of salt-treated plants are presented in Fig. 2. The total plant $\mathrm{Na}^{+}$content was found to be $32 \%$ higher in eggplant than huckleberry. Although, the shoot $\mathrm{Na}^{+}$content was more elevated in eggplant than huckleberry, their respective percentages, relative to total content, were not significantly different $(81 \%$ for huckleberry and $79 \%$ for eggplant). Of the total shoot $\mathrm{Na}^{+}$ content, about $50 \%$ accumulated in the leaf blade of huckleberry, whereas eggplant accumulated about $81 \%$.
Root $\mathrm{Na}^{+}$content was $51 \%$ more elevated in eggplant than huckleberry.

\section{Oxidative Stress Damage and Activities of Antioxidant Enzymes}

The MDA content in the leaf did not significantly change in huckleberry, but was markedly elevated in eggplant (64\%) (Fig. 3). In the root, MDA also increased in eggplant (26\%), but was not significantly altered in huckleberry (Fig. 3).

CAT activity in huckleberry, remained unaltered in the leaf and root, whereas in eggplant, it significantly increased in the leaf (48\%), but decreased in the root (50\%) (Fig. 4). APX activity increased markedly in root and slightly in leaf of both plants under both treatments, although the activity was lower in eggplant root (16\%) than huckleberry root (29\%) (Fig. 5). GR activity significantly increased in root of 
A

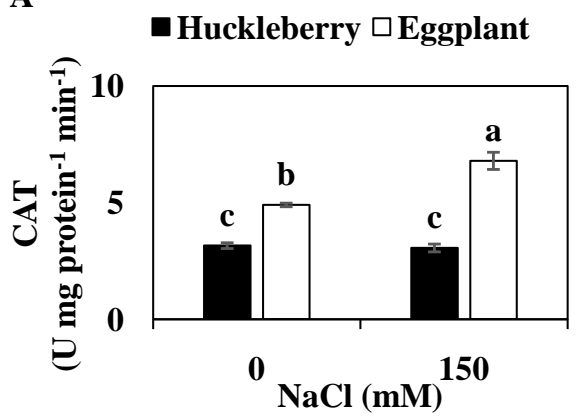

B

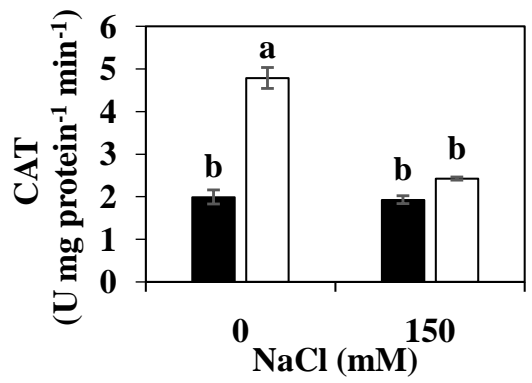

Fig. 4: Effect of salinity on CAT activity in the leaf (A) and root (B) of huckleberry and eggplant. The results represent the means $\pm \operatorname{SE}(n=4)$. The same letter indicates no significant difference $(p \leq 0.05)$

A

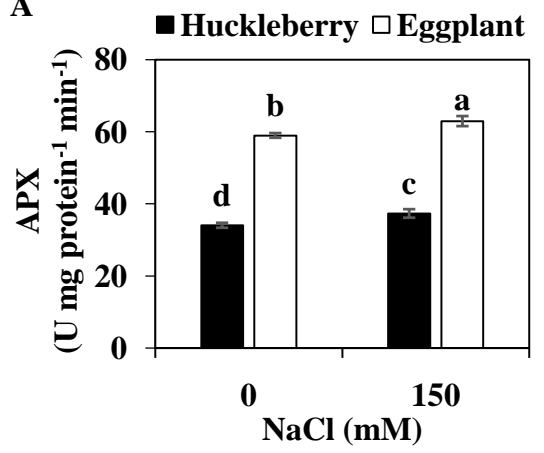

B

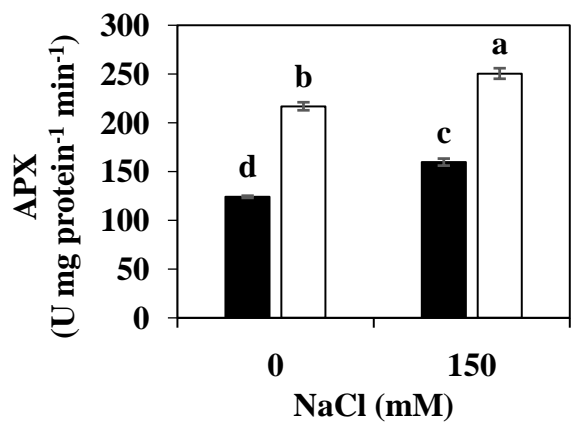

Fig. 5: Effect of salinity on APX activity in the leaf (A) and root (B) of huckleberry and eggplant. The results represent the means $\pm \operatorname{SE}(n=4)$. The same letter indicates no significant difference $(p \leq 0.05)$

A

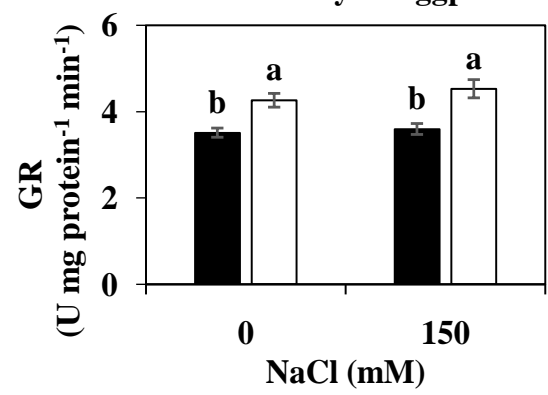

B

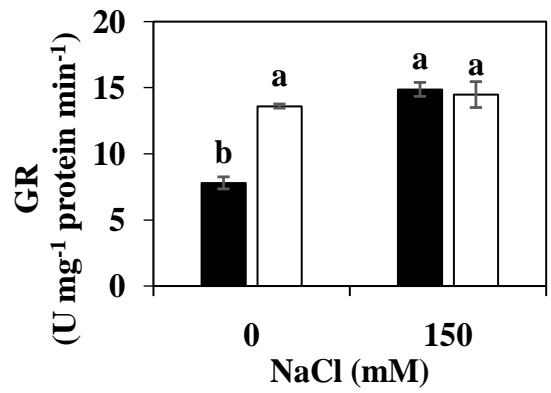

Fig. 6: Effect of salinity on GR activity in the leaf (A) and root (B) of huckleberry and eggplant. The results represent the means $\pm \operatorname{SE}(n=4)$. The same letter indicates no significant difference $(\mathrm{p} \leq 0.05)$

huckleberry (90\%), but no significant increase was observed in eggplant, whereas in the leaf there was no significant change in GR activity of both plants (Fig. 6). Salt stress did not significantly change the activity of sPOD activity in leaf of both plants (Fig. 7). In the root however, sPOD activity significantly increased in both plants, but this increase was more marked in huckleberry (2.7 fold) than eggplant (65\%) compared to the control plants (Fig. 7). The cwPOD activity in huckleberry showed a 2-fold and $34 \%$ increase in leaf and root, respectively, whereas in eggplant, it decreased $(40 \%$ and $23 \%$, respectively), although this decrease was not statistically significant (Fig. 8).

\section{Discussion}

The present study sought to examine the pattern of $\mathrm{Na}^{+}$ accumulation in different tissues of huckleberry and eggplant and to ascertain the effect of $\mathrm{Na}$ accumulation on antioxidant enzyme activity in leaf and root of both plants, under salinity stress. After subjecting both plants to high 

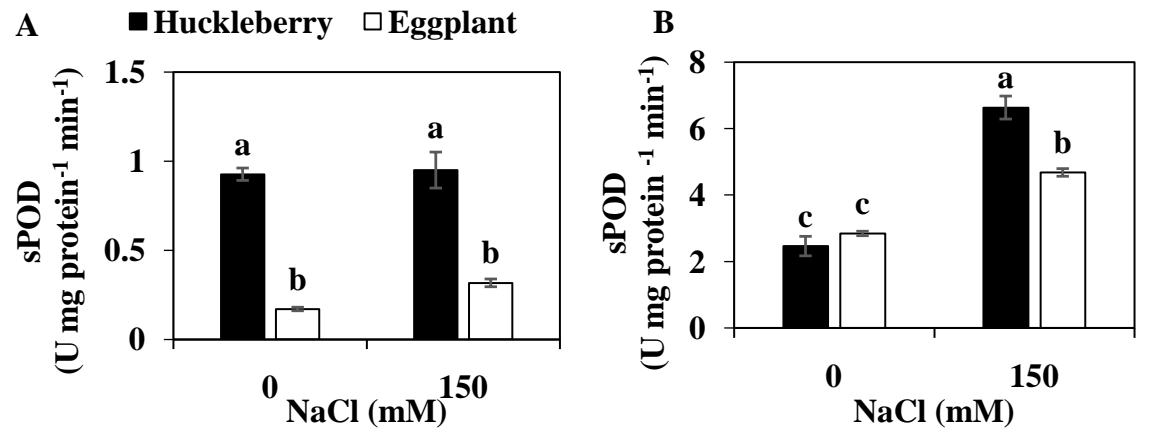

Fig. 7: Effect of salinity on SPOD activity in the leaf (A) and root (B) of huckleberry and eggplant. The results represent the means $\pm \operatorname{SE}(n=4)$. The same letter indicates no significant difference $(p \leq 0.05)$
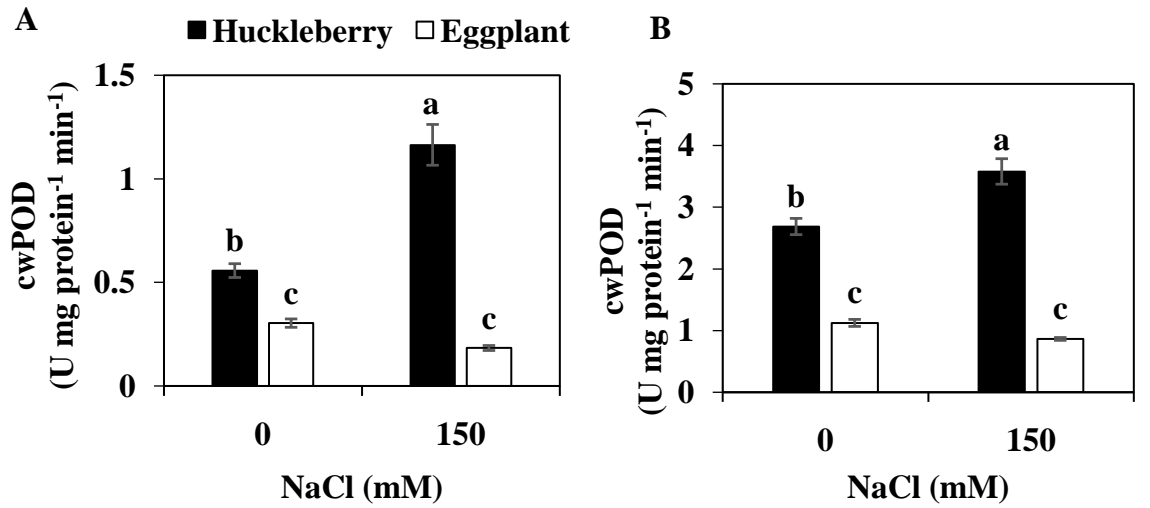

Fig. 8: Effect of salinity on cwPOD activity in the leaf (A) and root (B) of huckleberry and eggplant. The results represent the means $\pm \operatorname{SE}(n=4)$. The same letter indicates no significant difference $(\mathrm{p} \leq 0.05)$

salinity $(150 \mathrm{mM} \mathrm{NaCl})$ for $10 \mathrm{~d}$, the $\mathrm{Na}^{+}$concentration in huckleberry increased from the root to the stem and then progressively decreased through the petiole to the leaf blade (Table 1) yielding a more reduced $\mathrm{Na}^{+}$accumulation in its leaf blade $\left(44 \%\right.$ of total $\mathrm{Na}^{+}$) than eggplant $(63 \%$ of total $\mathrm{Na}^{+}$) (Fig. 2). This pattern offers further support to the existence of a mechanism of $\mathrm{Na}^{+}$exclusion to the leaf blade in huckleberry (Assaha et al., 2013). The present study further revealed that in addition to stem and root, the petiole also appears to be a potential control point for $\mathrm{Na}^{+}$delivery to the leaf blade. The leaf sheath has been shown to be a potential control point of $\mathrm{Na}^{+}$transport to the leaf blade in cereals under salinity. It contains the OsHKT1;4 transporter, which controls the delivery of $\mathrm{Na}^{+}$to the leaf blade by retrieving $\mathrm{Na}^{+}$from the transpiration stream in to xylem parenchyma cells (Hausser and Horie, 2010). Since the leaf sheath in the Poaceae is the equivalent of petiole in dicots, it is very likely that a similar control mechanism would exist in the petiole of huckleberry.

With reduced delivery of $\mathrm{Na}^{+}$to the leaf, the $\mathrm{Na}^{+} / \mathrm{K}^{+}$ ratio is usually kept low for normal metabolic processes to operate (Maathuis and Amtmann, 1999; Tester and Davenport, 2003). This lower $\mathrm{Na}^{+} / \mathrm{K}^{+}$ratio, as shown for huckleberry in the present study, is important for plants under salinity stress, as $\mathrm{K}^{+}$is the most abundant element in plants, intervening in many biological processes including enzyme activation, transport of sugars, stomatal regulation and osmoregulation (Hu and Schmidhalter, 2005).

In the present study, oxidative stress damage was assessed by measuring the MDA content in leaf and root of both plants. The MDA content in root and leaf of eggplant was significantly elevated, but remained unaltered in huckleberry (Fig. 3). This is a clear sign that there is saltinduced oxidative stress damage in these tissues in eggplant. The increase in MDA associated with sensitivity and a decrease associated with tolerance, have been reported in many cultivars of plants including sesame (Koca et al., 2007), maize (Azevedo-Neto et al., 2006), sugar beet (Bor et al., 2003) and rice (Demiral and Türkan, 2005). In these studies, low MDA corresponded to increased antioxidant enzyme activity, indicating a protective mechanism against oxidative damage. However, in the present study, evaluation of antioxidant enzyme activity in the leaf showed a marked increase in CAT activity in eggplant, where there was a corresponding $\mathrm{Na}^{+}$accumulation, but this enhanced activity apparently did not offer enough protection to the plants, similar to the observations of Shaheen et al. (2012). Although CATs are specific $\mathrm{H}_{2} \mathrm{O}_{2}$ scavengers, they operate 
with very low affinity for it when compared other antioxidant enzymes such as APX (Sharma et al., 2012) indicating that the production of ROS in the leaf was above CAT scavenging capacity in eggplant and coupled with lower APX and GR activities, induction of oxidative stress was unavoidable resulting in growth reduction. Huckleberry, on the contrary, maintained almost unaltered activities of CAT, GR, APX and sPOD in the leaf, where $\mathrm{Na}$ accumulation was low, indicating reduced $\mathrm{Na}$ toxicity in the leaf.

In the root on the other hand, the MDA content had the same trend like in the leaf, although the content was much lower (Fig. 3). Whereas huckleberry maintained an unaltered level of CAT, but enhanced SPOD, APX and GR activities, eggplant had a sharp decrease in CAT activity, and an increase in APX indicating that the latter alone was not sufficient to control the ROS produced in root of eggplant. APX and GR are key enzymes in the HalliwellAsada pathway (Sharma et al., 2012), which is considered more effective in scavenging ROS hence enhanced protection against oxidative stress (Koca et al., 2007, Yazici et al., 2007). The enhanced activity of the two enzymes in the root of huckleberry in combination with SPOD indicated that huckleberry has a better capacity of containing ROS than eggplant. Since high root $\mathrm{Na}$ in eggplant corresponded to a reduction in CAT activity, it is possible that catalase in activation by salt stress occurred (Tejera et al., 2007).

Oxidative stress has also been shown to induce $\mathrm{K}^{+}$ efflux from roots under salinity stress (Cuin and Shabala, 2007), a phenomenon that is thought to negatively affect growth (Shabala et al., 2005; Chen et al., 2007). In the present study, $\mathrm{K}^{+}$decreased in leaf and root of both plants, but the decrease was more marked in eggplant than in huckleberry, especially in the root (Table 2), where there was a corresponding elevated $\mathrm{Na}^{+} / \mathrm{K}^{+}$ratio (Fig. 1) and MDA (Fig. 3). This suggests that besides selective inhibition of $\mathrm{K}^{+}$uptake under salinity (Tester and Davenport, 2003), oxidative stress-induced efflux from the root (Cuin and Shabala, 2007) could also contribute to the decrease in root $\mathrm{K}^{+}$of eggplant.

The cwPODs are generally known to be implicated in the process of lignification (Boerjan et al., 2003). Lignification has been shown to affect plant growth under salinity stress (Neves et al., 2010). Enhanced activity of this enzyme under salinity is an indication of enhanced lignin deposition and since it uses $\mathrm{H}_{2} \mathrm{O}_{2}$ as a substrate in the process, it could also indicate enhanced ROS detoxification, hence enhanced tolerance (Maia et al., 2013). In the present study, the activity of cwPOD increased markedly in the root and leaf of huckleberry but decreased in eggplant in both organs, although this decrease was not statistically significant (Fig. 8). The increased cwPOD in huckleberry coincided with an unaltered MDA content indicating that this enzyme could play a protective role against oxidative stress in both organs, especially in the leaf, where all the other enzymes were not significantly altered. Also, this enhanced activity suggests enhanced deposition of lignin in these organs, which is in agreement with the findings of Sanchez-Aguayo et al. (2004). Lignin deposition inhibits cell elongation and eventually the growth of tissue or organ (Neves et al., 2010), indicating that the more reduced root DW in huckleberry compared with eggplant could be due to enhanced lignification in the root. However, under salt stress, this enhanced lignification could potentially contribute to the inhibition of $\mathrm{Na}$ influx into cells (Jbir et al. 2001). This inhibition of $\mathrm{Na}^{+}$influx has been suggested as an adaptive mechanism to control root-to-shoot $\mathrm{Na}^{+}$delivery under salinity (Karahara et al., 2004; Krishnamurthy et al. 2011), implying that the decreased activity of cwPOD in eggplant would correlate with reduced capacity for ROS detoxification as well as uncontrolled radial movement of solutes to the transpiration stream, thus allowing the free flow of $\mathrm{Na}^{+}$to the leaf, where it accumulates and causes oxidative stress damage.

\section{Conclusion}

The adaptation of huckleberry to salinity involves mechanisms for $\mathrm{Na}^{+}$exclusion in the leaf blade possibly located in the root, stem and petiole and enhanced antioxidant enzyme activity in the root. Although cwPOD is known to function primarily in lignin biosynthesis, especially in the root, its enhanced activity in the leaf of huckleberry, indicates a major role in ROS detoxification. Thus, in addition to conventional antioxidant enzymes, enhanced activity of cwPOD in leaf under salinity could constitute an important mechanism of stress adaptation.

\section{References}

Abogadallah, G.M., 2010. Antioxidative defense under salt stress. Plant Signal. Behav., 5: 369-374

Assaha, D.V.M., A. Ueda and H. Saneoka, 2013. Comparison of growth and mineral accumulation of two solanaceous species, Solanum scabrum Mill. (huckleberry) and $S$. melongena L. (eggplant), under salinity stress. Soil Sci. Plant Nutr., 59: 912-920

Azevedo-Neto, A.D., J.T. Prisco, J. Eneas-Filho, C.E.B. Abreu and E. Gomes-Filho, 2006. Effects of salt stress on antioxidative enzymes and lipid peroxidation in leaves and roots of salt-tolerant and saltsensitive maize genotypes. Environ. Exp. Bot., 56: 87-94

Boerjan, W., J. Ralph and M. Baucher, 2003. Lignin biosynthesis. Ann. Rev. Plant Biol., 54: 519-546

Bor, M., F. Özdemir and I. Türkan, 2003. The effects of salt stress on lipid peroxidation and antioxidants in leaves of sugar beet Beta vulgaris L. and wild beet Beta maritime L. Plant Sci., 164: 77-84

Chance, B. and A.C. Maehly, 1955. Assay of catalases and peroxidases. Meth. Enzymol., 2: 764-775

Chen, Z., T.A. Cuin, M. Zhou, A. Twomey, B.P. Naidu and S. Shabala, 2007. Compatible solute accumulation and stress-mitigating effects of barley genotypes contrasting in their salt tolerance. J. Exp. Bot., 58: $4245-4255$

Cuin, T.A. and S. Shabala, 2007. Compatible solutes reduce ROS-induced $\mathrm{K}^{+}$efflux in Arabidopsis roots. Plant Cell Environ., 30: 875-885

Demiral, T. and I. Türkan, 2005. Comparative lipid peroxidation, antioxidant defense systems and proline content in roots two rice cultivars differing in salt tolerance. Environ. Exp. Bot., 53: 247-257

Dionisio-Sese, M.L. and S. Tobita, 1998. Antioxidant responses of rice seedlings to salinity stress. Plant Sci., 135: 1-9 
Gill, S.S. and N. Tuteja, 2010. Reactive oxygen species and antioxidant machinery in abiotic stress tolerance in crop plants. Plant Physiol. Biochem., 48: 909-930

Hausser, F. and T. Horie, 2010. A conserved primary salt tolerance mechanism mediated by HKT transporters: a mechanism for sodium exclusion and maintenance of high $\mathrm{K}^{+} / \mathrm{Na}^{+}$ratio in leaves during salinity stress. Plant Cell Environ., 33: 552-565

$\mathrm{Hu}, \mathrm{Y}$. and U. Schmidhalter, 2005. Drought and salinity: a comparison of their effects on mineral nutrition of plants. J. Plant Nutr. Soil Sci., 168: $541-549$

Jaleel, C.A., R. Gopi, P. Manivannan and R. Panneerselvam, 2007. Antioxidative potentials as protective mechanism in Catharanthus roseus (L.) G. Don. plants under salinity stress. Turk. J. Bot., 31: 245251

Jbir, N., W. Chaibi, S. Ammar, A. Jemmali and A. Ayadi, 2001. Root growth and lignification of two wheat species differing in their sensitivity to $\mathrm{NaCl}$, in response to salt stress. Plant Biol. Pathol., 324: 863-868

Karahara, I., A. Ikeda, T. Kondo and Y. Uetake, 2004. Development of the Casparian strip in primary roots of maize under salt stress. Plantarum, 219: 41-47

Koca, H., M. Bor, F. Özdemir and I. Türkan, 2007. The effect of salinity stress on lipid peroxidation, antioxidative enzymes and proline content of sesame cultivars. Environ. Exp. Bot., 60: 344-351

Krishnamurthy, P., K. Ranathunge, S. Nayak, L. Schreiber and M.K. Mathew, 2011. Root apoplastic barriers block Na transport to shoots in rice (Oryza sativa L.). J. Exp. Bot., 62: 4215-4228

Lee, Y., M.C. Rubio, J. Alassimone and N. Geldner, 2013. A mechanism for localized lignin deposition in the endodermis. Cell, 153: 402-412

Lin, C.C. and C.H. Kao, 2001. Cell wall peroxidase activity, hydrogen peroxide level and $\mathrm{NaCl}$-inhibited root growth of rice seedlings. Plant Soil, 230: 135-143

Maathuis, F.J.M. and A. Amtmann, 1999. $\mathrm{K}^{+}$nutrition and Na toxicity: the basis of cellular $\mathrm{K}^{+} / \mathrm{Na}^{+}$ratios. Ann. Bot., 84: 123-133

Maia, J.M., E.L. Voigt, S.L. Ferreira-Silva, A.V. Fontenele, C.E.C. Macedo and J.A.G. Silviera, 2013. Differences in cowpea root growth triggered by salinity and dehydration are associated with oxidative modulation involving types I and III peroxidases and apoplastic ascorbate. J. Plant Growth Regul., 32: 376-387

Mittler, R., 2002. Oxidative stress, antioxidants and stress tolerance. Trends Plant Sci., 7: 405-410

Møller, S.I., M. Gilliham, D. Jha, G.M. Mayo, S.J. Roy, J.C. Coates, J. Haseloff and M. Tester, 2009. Shoot exclusion and increased salinity tolerance engineered by cell type-specific alteration of $\mathrm{Na}^{+}$transport in Arabidopsis. Plant Cell, 21:2163-2178
Munns, R. and M. Tester, 2008. Mechanisms of salinity tolerance. Annu. Rev. Plant. Biol., 59: 651-81

Neves, G.Y.S., R. Marchiosi, M.L.L. Ferrarese, R.C. Siqueira-Soares and O. Ferrarese-Filho, 2010. Root growth inhibition and lignification induced by salt stress in soybean. J. Agron. Crop Sci., 196: 467-473

Quiroga, M., C. Guerrero, M.A. Botella, A. Barcel, I. Amaya, M.I. Medina, F.J. Alonso, S.M. de Forchetti, H. Tigier and V. Valpuesta, 2000. A tomato peroxidase involved in the synthesis of lignin and suberin. Plant Physiol., 122: 1119-1127

Sairam, R.K. and A. Tyagi, 2004. Physiology and molecular biology of salinity stress tolerance in plants. Curr. Sci., 86: 407-421

Sanchez-Aguayo, I., J.M. Rodriguez-Galan, R. Garcia, J. Torreblanca and J.M. Pardo, 2004. Salt stress enhances xylem development and expression of S-adenosyl-L-methionine synthase in lignifying tissues of tomato plants. Plantarum, 220: 278-285

Saneoka, H., R.E.A. Moghaieb, G.S. Premachandra and K. Fujita, 2004. Nitrogen nutrition and water stress effects on cell membrane stability and leaf water relations in Agrostis palustris Huds. Environ. Exp. Bot., 52: 131-138

Shabala, L., T.A. Cuin, I.A. Newman and G. Shabala, 2005. Salinityinduced ion flux patterns from the excised roots of Arabidopsis sos mutants. Plantarum, 222: 1041-1050

Shaheen, S., S. Naseer, M. Ashraf and N.A. Akram, 2012. Salt stress affects water relations, photosynthesis and oxidative defense mechanisms in Solanum melongena $\mathrm{L}$. J. Plant Interact., 12: 1-12

Sharma, P., A.B. Jha, R.S. Dubey and M. Pessarakli, 2012. Reactive oxygen species, oxidative damage, and antioxidant defense mechanism in plants under stressful conditions. J. Bot., article ID 217037

Takagi, H. and S. Yamada, 2013. Roles of enzymes in anti-oxidative response system on three species of chenopodiaceous halophytes under NaCl-stress condition. Soil Sci. Plant Nutr., 59: 603-611

Tejera, N.A., C. Iribarne, F. Palma and C. Lluch, 2007. Inhibition of the catalase activity from Phaseolus vulgaris and Medicago sativa by $\mathrm{NaCl}$. Plant Physiol. Biochem., 45: 535-541

Tester, M. and R. Davenport, 2003. $\mathrm{Na}^{+}$tolerance and $\mathrm{Na}^{+}$transport in higher plants. Ann. Bot., 91: 503-527

Yazici, I., I. Türkan, A.H. Sekmen and T. Demiral, 2007. Salinity tolerance of purslane (Portulacaoleracea L.) is achieved by enhanced antioxidative system, lower level of lipid peroxidation and proline accumulation. Environ. Exp. Bot., 61: 49-57

(Received 13 September 2014; Accepted 12 January 2015) 